\title{
Research on Talent Cultivation of Financial Big Data*
}

\author{
Xiaoyu Liu \\ Harbin Finance University \\ Harbin, China
}

\begin{abstract}
This paper analyzes the challenges faced by the training of financial big data talents, and constructs the super network model of financial big data talents training.
\end{abstract}

Keywords-super network; financial big data; personnel training

\section{INTRODUCTION}

As the focus of the current society, "big data" has changed the way of thinking of human beings. In the era of big data, the research field is becoming more and more extensive. It is mainly embodied in the combination of different majors and big data, which can produce new research fields and disciplines. At present, the big data has become the development trend of the global financial industry, has received the widespread attention, the financial industry, the development of large financial data on the one hand, change the management mode, on the other hand to change the talent needs of the financial industry. The traditional banking industry needs the financial economy and other relevant professional talents, but now it needs the complex talents related to finance, computer and Internet. National medium and long-term development plan outline (2010-2020), highlighted the problem facing the problems and challenges of talents cultivation, in August 2015, the state council executive meeting passed the big data development outline, this marks a big data is more and more attention.

\section{Challenges FaCED By the TAlent Cultivation OF FINANCIAL BIG DATA}

\section{A. Education Subject}

Big financial data related to professional and subject construction must have the perfect teacher talent system, but the real situation, at the same time grasp the big data technology, have experience in big data applications of professional teachers is still very few. For example, proficient in Hadoop technology and MapReduce algorithm,

*Foundation item: The research project of the basic scientific research project of the province of Harbin Finance University, which is based on the financial ethics perspective, the research stage of the financial development evaluation of the county area, project number: 2017-kyywf-0088; Teaching reform project of higher education in Heilongjiang province: the

exploration and research stage of the talent cultivation of financial big data. Project number: SJGZ20170027 familiar with Oracle, Hive and other database management and use technologies, proficient in data mining and statistical analysis programming languages such as $\mathrm{C}++$, SAS, JAVA etc. The shortage of teachers' talents and the unsound system resulting from it are the challenges facing the discipline and professional construction. America's 20 top universities design data in the talent training scheme, determine the 6 core courses, they are big data analysis, basic statistics, data analysis, basic computer, data mining and machine learning, big data distributed computing, data modeling, case studies and unstructured data analysis. Different with other colleges and universities are the core courses are taught by a teaching team, not by a teacher to teach alone, it is conceivable that the power of the teaching team is much higher than that of single professor, and the teaching method is not traditional is given priority to with teacher's teaching, but with the method of class discussion, through collaborative innovation, improve the teaching level. Obviously, this poses a challenge to the teachers of education.

\section{B. Education Object}

Financial data analysis belongs to the interdisciplinary, in addition to the basic knowledge of finance, statistics statistical modeling, data mining, etc., also need to have knowledge of computer science background in the field of application, according to the mission requirements, such as comprehensive utilization of all kinds of computer technology and knowledge, collect, sort out massive amounts of data to support the decision-making and behavior of data preparation; Master SAS, R and statistical analysis of data mining in a programming language, proficient in association rules, cluster analysis, discriminant analysis, data stream mining, text mining, neural network, social network, support vector machine and big data mining technologies such as statistical modeling skills and related algorithm. The potential value of Banks and other financial industries is found in the vast amount of data. Therefore, the specific statistical problems are extracted and the specific financial services are raised. Colleges and universities in training plan and scheme, mathematics, statistics, computer science should be paid attention to the organic fusion and application in the field of in-depth, according to the specific requirements, the effective method and model analysis data, and report form, offer the decision basis for the actual problem. 


\section{CONSTRUCTION OF SUPERNETWORK MODEL OF FinANCIAL Big Data TALENT CUlTiVATION}

In 2002, Anna Nagurney first proposed a supernetwork definition: a network that is both higher than and beyond the general network, and can be understood as the system that contains the network in a network of nodes. Big financial data on the cultivation of the whole process and other professional talents, by contrast, is more complicated and the different elements of the system is also more complicated, which requires all kinds of different concentration are processed together, the elements of super network can solve the above problem. Therefore, based on the analysis of supernetwork structure and characteristics, this paper establishes a supernetwork model of financial big data talent cultivation. Among them, the super network model includes professional curriculum construction network, application ability of knowledge network, talent of jobs in the mapping relationship between and among the networks, namely professional curriculum construction mapping between network and knowledge application ability of the network, the application ability of knowledge network and talent employment network mapping between, professional curriculum construction and the mapping between the talent employment network. The three networks of the model correspond to three nodes, which are specialized course construction nodes, knowledge application ability nodes, and talents' employment post nodes. There is a close relationship between the three nodes. For example, the reasonable application of professional curriculum construction can help the application of knowledge ability, and the ability of talents to be qualified for employment must have the application ability of professional knowledge. After formalizing the hypernetwork model, it is expressed as.

$$
K Z R=\left(G_{k}, G_{z}, G_{r}, E_{k-z}, E_{z-r}, E_{k-r}\right)
$$

\section{A. Professional Curriculum Construction Network( $K-K$ Network)}

The professional curriculum construction network represents the curriculum and the relationship between the higher education institutions and the higher education institutions. The professional course is the node, with the relationship between the specialized courses as the edge, can establish the network which is composed by the specialized course construction node. ( $K-K$ network). The form can be expressed as $G_{k}=\left(K, E_{k-k}\right), K=\left\{k_{1}, k_{2}, \ldots k_{i}\right\}$ Represents a set of nodes for all specialized courses, $E_{k-k}=\left\{\left(k_{p}, k_{q}\right) \mid k_{p}, k_{q} \in Z\right\} p, q=1,2 \ldots k$ represents the set of edges, $\left(k_{p}, k_{q}\right)$ show that $k_{p}$ and $k_{q}$ is a logical relationship, it can be understood as the timing and related types of two specialized course nodes.

\section{B. Knowledge Application Capacity Network. ( $Z-Z$ Network)}

Knowledge power network is the financial data of the application of the talent training super network model on the basis of the network, said the big data talents should have knowledge of the application of the relationship between the ability and application ability of knowledge. With the application ability of knowledge as the node, the relationship between the application ability of knowledge is the edge, and the network composed of knowledge and skill nodes is established ( $Z-Z$ network). The form can be expressed as $G_{z}=\left(Z, E_{z-z}\right), \quad Z=\left\{z_{1}, z_{2} \ldots z_{i,}\right\}$ show that a collection of application capability nodes for all knowledge. ; $E_{z-z}=\left\{\left(z_{p}, z_{q}\right) \mid z_{p}, z_{q} \in Z\right\} p, q=1,2 \ldots k$ represents the set of edges, $\left(z_{p}, z_{q}\right)$ show that $z_{p}$ and $z_{q}$ is a logical relationship, that is, the domain and content of the two knowledge application capability nodes.

\section{The Job Network of Talented Person ( $R-R$ Network)}

The employment network of talents indicates that the financial industry provides various jobs and interconnections among financial big data talents. With the employment of talents as the node, the relationship between the talents' employment position is the edge, and the network of job posts of talents is established. ( $R-R$ network), The form can be expressed as $G_{r}=\left(\mathrm{R}, E_{r-r}\right), R=\left\{r_{1}, r_{2} \ldots r_{i}\right\}$ represents the collection of jobs for all talents. $E_{r-r}=\left\{\left(r_{p}, r_{q}\right) \mid r_{p}, r_{q} \in Z\right\} p, q=1,2 \ldots k$ represents the set of edges , $\left(r_{p}, r_{q}\right)$ show that $r_{p}$ ang $r_{q}$ is a logical relationship, that is, the level of employment of two talents is related to function.

\section{Mapping between the Networks in the Model}

There are not only three kinds of networks in the supernetwork model of financial big data talent training. $G_{k}, G_{z}, G_{r}$, it also contains mapping between the three networks: $E_{k-z}, E_{z-r}, E_{k-r}$, On behalf of the professional curriculum construction network, knowledge of the application capacity network and the job post network of talents. Specific performance is as follows:

- Mapping between professional curriculum construction network and knowledge application capability network. The set of relationships between the professional curriculum building network and the application capability network of knowledge can be expressed as. $E_{k-z}$, there are two kinds of mapping in the collection in $E_{k-z}$ : the mapping of professional curriculum construction to the application ability of knowledge and the mapping of the application ability of knowledge to the construction of specialized courses. The application ability of knowledge to the mapping of professional curriculum construction indicates that financial big data talents have the knowledge of application ability and need to set relevant professional courses. $K(z p)$ shows that demonstrate mastery of the application of knowledge 
$z p$ a collection of related specialized courses to be set up, $K(z p)=\{k q \mid k q \in K, \theta(z p, k q)=1\} \quad$, $\theta(z p, k q)=1$ Represents the application ability of knowledge. $z p$ to professional course construction $k q$ there is a one-to-one correspondence; The mapping of professional curriculum construction to the application ability of knowledge represents the construction of specialized courses, $k q$ show that The ability to train financial big data talents should be equipped with knowledge. $z p \cdot Z(k p)$ represents the construction of specialized courses. $k q$ shows that a collection of applications capable of fostering the knowledge of financial big data. $Z(k p)=\{z q \mid z q \in Z, \theta(k p, z q)=1\}, \quad \theta(k p, z q)=1$ is a one-to-one correspondence between the construction of specialized courses and the application ability of knowledge.

- The mapping between the knowledge application capacity network and the job post network of talents.

- The relationship between the network of knowledge and the job post network of talents can be expressed as. $E_{z-r}$, It's in the $E_{z-r}$ set there are two mapping relationships, the application ability of knowledge to the mapping of talent's job position and the employment of talents to the application ability of knowledge. The mapping of the application ability of knowledge to the employment of talents indicates that financial big data talents need to have the knowledge application ability to be competent for which jobs. $R(z p)$ show that the ability to apply the knowledge of financial big data. zp show that a collection of posts to be engaged in. $\quad R(z p)=\{r q \mid r q \in R, \theta(z p, r q)=1\} \quad$,

$\theta(z p, r q)=1$ is a one-to-one correspondence between the application ability of the knowledge of financial big data talents and the employment of talents. The mapping of the employment of talents to the application ability of knowledge indicates that the employment position of financial big data talents requires the application ability of knowledge. $Z(r p)$ shows that a competent job. $r p$ financial big data person should have knowledge skill set. , $Z(r p)=\{z q \mid z q \in Z, \theta(r p, z q)=1\}, \quad \theta(r p, z q)=1$ show that the employment of talents $r p$ and the ability to apply the knowledge of financial big data talents. $z q$ is a one-to-one correspondence.

- The mapping between the professional curriculum construction network and the job post network of talents.

- The collection of professional curriculum construction network and job post network can be expressed as. $E_{k-r}$.In a set of $E_{k-r}$, there are two kinds of mapping relationship: the mapping of professional curriculum construction to the employment of talents and the mapping of talents' employment to professional curriculum construction. The mapping of the professional curriculum to the employment of talents indicates that the professional courses related to financial big data talents can be obtained. $R(k p)$ means that financial big data professionals can learn which specialized courses can be qualified for the collection of job positions. $R(k p)=\{r q \mid r q \in R, \theta(k p, r q)=1\} \quad$.

$\theta(k p, r q)=1$ show that a one-to-one correspondence between the professional courses related to the study of financial big data and the employment of talents. The mapping of the employment of talents to the construction of specialized courses indicates that the job positions of talents need financial big data talents to learn which specialized courses. $Z$ ( $r p)$ means that the job position of obtaining talents requires a collection of specialized courses related to the study of financial big data talents. $Z(r p)=\{z q \mid k q \in K, \theta(r p, k q)=1\} \quad$, $\theta(r p, k q)=1$ represent the employment of talents $r p$ There is a one-to-one correspondence between the major courses $\mathrm{kq}$ related to financial big data talents.

\section{CONCLUSION}

To sum up, the big data talents cultivation $K Z R$ model is the professional network, knowledge application ability of the network course construction and talented person's employment network in the network, network, knowledge application ability of the network is the core of the model, three nodes network dependent relationship to one another, and those who have a single type, compared to a network of nodes and the relationship between financial talent training super large data network model can more accurately reflect the complexity of talent fostering the big data, so the $K Z R$ model can be formulated in colleges and universities financial big data the talent training scheme has important significance.

\section{REFERENCES}

[1] Zhao Yongping, Xu Ying. Research on industry-university-research collaborative innovation based on core - peripheral hypernetwork model . Journal of dalian university of technology. 4th ed., vol. 8. Social Science Edition, 2013, pp.7-12.

[2] Shi Xiusong. Preliminary exploration on the cultivation of application talents in local colleges and universities under big data environment. 2ed., vol. 11. Theoretical observation, 2013, pp.134-135.

[3] Lu Shenfeng.Analysis on the reform of finance under the backgrong of big data. 2ed., vol. 15,.Journal of hubei university of econmics, 2015 pp.170-171. 